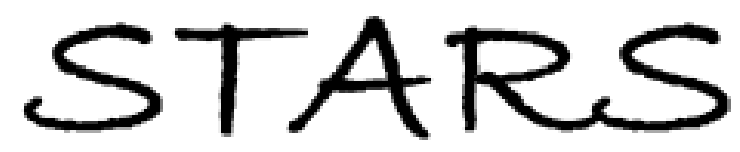

University of Central Florida

STARS

$1-1-2011$

\title{
Capoeira as a Clinical Intervention: Addressing Adolescent Aggression With Brazilian Martial Arts
}

Isaac Burt

S. Kent Butler

University of Central Florida

Find similar works at: https://stars.library.ucf.edu/facultybib2010

University of Central Florida Libraries http://library.ucf.edu

This Article is brought to you for free and open access by the Faculty Bibliography at STARS. It has been accepted for inclusion in Faculty Bibliography 2010 s by an authorized administrator of STARS. For more information, please contact STARS@ucf.edu.

\section{Recommended Citation}

Burt, Isaac and Butler, S. Kent, "Capoeira as a Clinical Intervention: Addressing Adolescent Aggression With Brazilian Martial Arts" (2011). Faculty Bibliography 2010s. 1125.

https://stars.library.ucf.edu/facultybib2010/1125

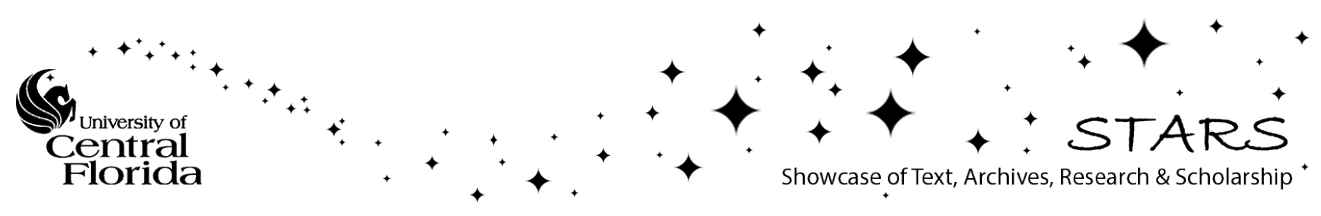




\title{
Capoeira as a Clinical Intervention: Addressing Adolescent Aggression With Brazilian Martial Arts
}

\author{
Isaac Burt and S. Kent Butler
}

Aggression in adolescents is harmful and emotionally devastating to youth and surrounding communities. This article integrates martial arts and therapeutic principles into a culturally sensitive model that cultivates change in the aggressive behaviors of disenfranchised adolescents. The art form of Capoeira is proposed for promoting positive behavioral change.

La agresión en los adolescentes es dañina y emocionalmente devastadora para los jóvenes y sus comunidades. Este artículo integra artes marciales y principios terapéuticos en un modelo culturalmente sensible que cultiva el cambio de los comportamientos agresivos de los adolescentes marginalizados. Se propone el arte de la Capoeira para promover un cambio positivo en el comportamiento.

$\mathrm{V}$

lolence is an increasing aspect of life in modern-day society that is emotionally devastating to youth, neighborhoods, communities, and educational institutions (U.S. Department of Justice, 2001). During the past 10 years, aggression has expanded exponentially, resulting in some adolescents bringing guns to schools (U.S. Department of Education, 2000). After committing violent acts, troubled youth spend valuable time in detention centers, jails, or residential institutions (Small, Kennedy, \& Bender, 1991). Many of these establishments are ineffective in resolving behavioral problems of aggressive adolescents (Wells, 1991). In addition, ethnic minority adolescents, who are overwhelmingly Black and Hispanic, suffer from unfair placement into correctional facilities as a result of racism and implicitly negative social practices (Piquero, 2008).

Literature indicates that, once released into mainstream society, many poorly rehabilitated youth relapse into aggressive behaviors because of poor selfefficacy and socialization skills (Bandura, 1997). Coupled with convenience and limited access to mental health care, placement of aggressive adolescents into residential facilities is rapidly becoming standard procedure (Twemlow, Sacco, \& Fonagy, 2008). However, many correctional facilities have not been shown to be an effective intervention for aggressive youth. Furthermore, correctional institutions are costly to taxpayers and are a strain on governmental resources (Twemlow \& Sacco, 1998).

Isaac Burt, Department of Counseling and Development, Long Island University, C.W. Post Campus, Brookville, New York; S. Kent Butler, Counselor Education Program, University of Central Florida, Orlando. Correspondence concerning this article should be addressed to Isaac Burt, Department of Counseling and Development, Long Island University, C.W. Post Campus, Library, Room 320, College of Education and Information Sciences, 720 Northern Boulevard, Brookville, NY 11548 (e-mail: ibtnh2@aol.com). 
According to Twemlow and Sacco (1998), recidivism is high when a residential facility is the sole intervention for aggressive behaviors in adolescents. There is need for culturally sensitive, effective, and affordable programs to augment residential treatments. Twemlow and Sacco proposed that a traditional martial art, when integrated with clinical components, is a viable addendum to correctional facilities. Twemlow and Sacco's work draws on research conducted by Kurian, Caterinio, and Kulhavy (1993) and substantiated by Law (2004) and Parmigiani et al. (2006).

Martial arts represent a paradigm shift from talk therapies to more interactive, socially involving group methods of treatment (Nosanchuk, 1981). A martial art that is culturally responsive, concrete, and easy to use is required to support the therapeutic process (Lamarre \& Nosanchuk, 1999). Twemlow, Sacco, and Fonagy (2008) stated that aggressive adolescents normally do not respond well to traditional therapies alone. Combining the active movement of martial arts with therapeutic principles can make a significant difference in drawing these challenging adolescents into considering changing lifestyles.

Capoeira, originating in Brazil, may serve as a pragmatic martial art/clinical model that promotes cultural sensitivity for marginalized youth, collective action in performance, self-efficacy in individual youth, and positive perceptions of personal capabilities (Capoeira, 2003). These concepts are similar to the self-efficacy tenets Bandura (1997) postulated that people need for positive functioning in society. More specifically, martial arts can provide aggressive adolescents with nonviolent approaches that reinforce determination, goal orientation, prosocial bonds, and positive role modeling (Twemlow, Biggs, et al., 2008).

Roysircar (2009) advocated for culturally sensitive treatments that provide effective interventions and/or modify a Western therapy in ways that speak to the needs of culturally diverse clients. Roysircar contended that a culturally sensitive perspective is needed to assist historically underserved and underrepresented ethnic minorities. In addition, Roysircar pointed out that adaptations of diagnoses, treatments, and perceptions of clients' wellness need changing if therapists are to be effective.

Research indicates that a gap exists in European interventions adequately meeting the needs of racially diverse clients. For example, the Behavioral Science Task Force of the National Advisory Mental Health Council (NAMHC; 1996) reported that there are four major impediments to providing appropriate mental health services to diverse clientele. First, there are differences in how people express the symptoms of mental health problems across cultures. Second, there is an adverse bias in some helping professionals' diagnoses of racial minorities. Third, diagnosis, treatment, and continued care for affected racial minorities come from individuals who may not value sensitive cultural values. Fourth, a large percentage of people from the majority culture are the primary providers of mental 
health services, resulting in distrust by racial minority clientele. Roysircar (2009) stated that culturally sensitive treatments address problems described by NAMHC through the incorporation of issues of ethnicity, diversity, oppression, and culture into counseling. The martial art form of Capoeira, integrated with mental health counseling, may provide a culturally sensitive treatment to work with aggressive adolescents who are marginalized and/or disenfranchised.

\section{characteristics of capoeira}

\section{DEFINITION OF TERMS}

Marginalized and disenfranchised adolescents, for the purposes of this article, refer to youth who (a) are ethnic minorities; (b) have low socioeconomic status; (c) receive minimal support and encouragement in schools, communities, and homes; and (d) have inadequate academic preparation (Hawkins, Catalano, \& Miller, 1992). Fondacaro and Weinberg (2002) stated that societal establishments do not allocate power equally because of societal biases about immigrant status, race, age, religious heritage, physical ability, or sexual orientation. Society relegates those deemed as different to subordinate roles and treats them accordingly (Bandura, 1986). Succinctly stated, society reacts to these individuals based on collectively created and given social roles (Lerner, 1982). As such, there needs to be an intervention that modifies the environment and proffers new societal roles (Bandura, 2001).

The American Heritage Dictionary (2006) defines martial arts as a mode of self-defense with influences from the Asian cultural art forms of Judo and Karate. Deceptively simple, this definition relegates martial arts to being rooted primarily in Asian cultures. However, this definition does not encompass the richness and complexity of the art form. Many countries, such as Brazil, have contributed to the growth and development of more contemporary forms of martial arts (Capoeira, 2003). In particular, Capoeira has characteristics that separate it from other styles of martial arts training, including its philosophy of nonphysical contact and an environment that advocates for teamwork (Capoeira, 2006). In addition, Capoeira's historical significance allows for a discourse on oppression, institutionalism, and issues of social class. Capoeira's historical relationship to oppression is an important culturally sensitive factor, and one discussed later in the article.

The environment found in Capoeira is similar to Coopersmith's (1967) recommendation that adolescents grow in (a) an atmosphere that is warm and supportive, (b) a social milieu that sets clear and attainable goals, and (c) a setting that provides autonomy. In addition, Capoeira creates an interactive environment that promotes discipline, respect for others, and less ego-centered 
beliefs (Boneco, 2002). This social milieu of Capoeira influences self-efficacy, reverence/appreciation for diversity, and an understanding of other people's dispositions and inclinations (Capoeira of San Jose, 2003). Through prosocial interactions among people, positive role modeling, and an emphasis on diversity and cultural awareness, positive change may occur (Capoeira, 2006). The prosocial interactions found in Capoeira are similar to Bandura's (1986) reciprocal determinism, which points out the triadic interaction among the environment, interpersonal factors, and behavior.

According to Capoeira (2003), no other martial art has these three prosocial therapeutic principles (Bandura, 1986) embedded within its framework. Through reciprocal determinism, Capoeira may provide for socialization and prosocial bonding in marginalized youth. For example, in Capoeira, practicing with someone else can become stressful because of the physical and psychosocial nature of the art. Capoeira's philosophy is that one should not allow anger to take over and lead to aggression. Poor performances by aggressive youth during Capoeira practice may result in depression due to their mistakes and lost opportunities. This feeling may stem from trying something new and feelings of vulnerability. However, these feelings should not deter one and take away hope.

Capoeira is not about winning or losing; it fosters thoughts about what went wrong; it develops pondering about environmental opportunities for one to become better and to train more appropriately in the future (Capoeira, 2006). In the previous example, reciprocal determinism in Capoeira includes the environment (practicing Capoeira), having an effect on the interpersonal factors of a person (disconnection, low attachment), and the behavior (aggression) that may come from the interaction among these factors.

\section{THEORETICAL UNDERPINNINGS}

Capoeira's greatest promise is around its positive approach to building wellness and self-efficacy. Instructors who are themselves positive models and who can identify positive strengths are critical. Social cognitive theory supports Capoeira. Bandura (1986) asserted that modeling is even more important when dealing with marginalized populations. In Capoeira, instructors have great mentorship responsibility because their behavior influences the actions, beliefs, and thoughts of students (Capoeira, 2006). This form of observational learning corresponds with studies showing that modeling in martial arts increases self-esteem, reduces aggressive behavior, and lowers levels of performance anxiety (Law, 2004). Capoeira has these therapeutic factors within its system as it creates a social environment that teaches more than just a simple regimen of kicks and acrobatics.

According to Bandura (1986), an environment that is responsive and flexible produces a high sense of self-efficacy, promotes well-being, and provides rich educational opportunities. An atmosphere created in this vein 
is analogous to the one Portes (1998) recommended marginalized youth need to go beyond the limitations that society has arbitrarily imposed on them. Capoeira develops a social environment unlike any other martial art, dance, or style, and this distinguishes it from other movement-based modalities (Capoeira, 2003). The social environment and reciprocal interaction found in Capoeira potentially move adolescents away from ego-centered beliefs and allows for a reduction in aggression (Capoeira, 2003). Improved social environments may benefit not only participants but also everyone involved because of collaborative participation in a prosocial environment.

\section{capoeira as a therapeutic intervention}

Research indicates that martial arts, when used therapeutically, enhance adolescent growth and development (Kurian et al., 1993). Twemlow and Sacco (1998) stated that marginalized adolescents, particularly ones who show aggressive behaviors, are reluctant to participate in traditional talk therapy. This reluctance stems from their perceptions that institutions that have oppressed them now want to establish therapeutic relationships with them (Constantine, Hage, Kindaichi, \& Bryant, 2007). Stated differently, marginalized adolescents see therapy as another method to subjugate them (Twemlow, Sacco, \& Williams, 1996). It is espoused that there needs to be a concrete, hands-on intervention that can capture marginalized adolescents' attention and motivate them to reduce their participation in violent acts (Twemlow \& Sacco, 1998). Twemlow, Sacco, and Fonagy (2008) showed that martial arts, with a commitment to respect and self-control and focusing on leadership and community service, are viable tools for reducing aggression in disenfranchised adolescents and developing positive character development. Capoeira takes these tenets a step further by incorporating leadership and self-control with a wellness or physical health component (Capoeira, 2003). Weisz, Sandler, Durlak, and Anton (2005) stipulated that by providing safe physical outlets, excessive energy expends naturally and anger expresses itself in a manner that builds adolescents' sense of physical and emotional balance.

Because adolescents are sometimes reluctant to engage in traditional talk therapies, Bernard (1991) recommended that practitioners working with marginalized adolescents utilize factors such as caring, support, and positive social participation. Bandura (1986) suggested that marginalized youth develop poor perceptions of their self-efficacy stemming from a lack of caring from adults and a dearth of positive socialization. Bandura (1997) further stated that an atmosphere dealing with adolescents must be flexible and adapt accordingly to the attributes that marginalized adolescents bring. These aspects include cultural, physical, and psychological factors. 


\section{A CULTURALLY SENSITIVE TREATMENT MODEL}

In the country of Brazil, there is a variety of people from different ethnic backgrounds. As such, acceptance and accommodation of differences are expected in this culture (Boneco, 2002). Capoeira acknowledges cultural sensitivity and acceptance of different ethnicities and ability levels as everyday facets of life, and these are fundamental tenets of the art (Boneco, 2002). In Capoeira, individuals are within an extended family setup, and this inclusion initiates a close relationship with others in a social environment (Capoeira, 2003). This type of supportive relationship is consistent with the literature that states adolescents gain behavioral and social benefits from knowing that someone cares and is concerned for their well-being (Hawkins et al., 1992). In Capoeira, socializing, enjoying time with peers, and enthusiastically praising advancements are strongly encouraged (Capoeira, 2003). Thus, marginalized adolescents may feel free to engage fully without fear of stigma or isolation (Small et al., 1991). For many culturally diverse populations, a familylike atmosphere is valued, and it puts clients more at ease in therapy (Day, 2004).

Capoeira's history allows for discourse on oppression, institutionalism, and social class. African slaves created Capoeira as a method of defense to protect themselves against slave masters (Capoeira, 2006). Brazilian slaves endured similar economic hardships and racial discriminations faced by slaves in the United States after the emancipation of slavery. As a result of racial discrimination, Capoeira was outlawed because of its connections to gangs, Blacks, and lower socioeconomic individuals (Capoeira, 2003). However, through positive socialization of its members and altering society's viewpoints, masters of Capoeira peacefully established the martial art in Brazilian society. Capoeira now stands as a national sport in Brazil, second to soccer in popularity. The creators of Capoeira pushed for institutional change and advocated for the rights and freedoms of disenfranchised individuals in Brazil.

Based on the history from which it was created, Capoeira lends itself to finding commonalities between marginalized individuals and, thus, building bridges. Witnessing that others have also persevered through discrimination and hardships peacefully may reduce marginalized adolescents' aggressive behaviors. This happens through vicarious learning (Bandura, 1997). Participants in Capoeira learn that the historical significance is of equal importance to the physical elements of the art. Leong and Lee (see Roysircar, 2009) stated in their Cultural Accommodation Model (CAM) three important concepts that need consideration when working with a minority population. CAM recognizes the commonalities across people, along with their group dimensions, and separates the individual from the group in an effort to understand ethnic minorities.

Capoeira incorporates the concepts proposed by Leong and Lee (as cited in Roysircar, 2009). Through the combination of the physical elements encom- 
passed in Capoeira and meaningful dialogue, the concepts of CAM materialize. For instance, participants recognize shared commonalities with one another such as marginalization and physical maturation, the value and significance of group identification, and that they must find their own methods to reduce aggressive behaviors (Capoeira, 2006).

\section{GANG PROCESSES}

Marginalized adolescents often feel they must fend for themselves, causing them to bully, steal, or fight perceived enemies. These youth have a significant need for group affiliation, positive or negative. They also have a need to feel powerful, and feelings of physical insecurity may influence aggressive acts and/or gang involvement (Rice \& Dolgin, 2005). They long for adult protection, which is often lacking. Their need for affiliation may result in involvement with a violent street gang, making adolescents feel that they are involved in something important as well as giving them a feeling of personal safety and connection (Twemlow \& Sacco, 1998).

Capoeira implements a methodology akin to that customary with gangs (Twemlow \& Sacco, 1998). Gangs use nicknames that designate a meaning or have an associated connotation, bestowing rank, power, prestige, and honor on the recipient (Capoeira, 2003). Unfortunately, many nicknames stem from hurting others or committing criminal acts (Twemlow \& Sacco, 1998). In Capoeira, names credit the positive attributes of participants, such as physical advancement in the art or socially appropriate behaviors (Capoeira, 2003). In gangs, a name is serious, as being bestowed a moniker is a great honor and marks the person not simply as an individual but as a member of the family (Twemlow \& Sacco, 1998). Capoeira uses this approach, with ranks and privileges (such as the responsibility of teaching) being awarded to the individual who is named. In this martial art, a person becomes a little brother or sister to students named before, and a big brother or sister to ones named after (Capoeira, 2003). Capoeira's approach to conferring names is, in essence, a token economy, with privileges earned by interacting positively. Kazdin (1989) supported the use of a token economy for adolescents as well as for children and adults because it can assist in modifying behavior in a positive direction.

\section{conclusion}

Capoeira, a martial art form from Brazil, may provide positive rewards when used effectively with marginalized adolescents (Capoeira, 2006). What is of primary importance is its philosophy of cultural sensitivity, awareness of historical oppression, and working together as a collaborative team (Capoeira, 2003). A martial arts program may provide an adolescent many opportunities to grow and achieve that he or she thought were never possible (Back \& Kim, 1979). Bandura (1997) and Portes (1998) both stated that marginalized adolescents and children, be- 
cause of societal prejudice, develop a poor sense of self-efficacy that is difficult to eliminate. Capoeira, integrated with clinical principles of behaviorism, may produce an environment that assists in reducing aggressive behavior through modeling, character development, and prosocial learning (Capoeira, 2006).

\section{limitations}

As with any modality, there are limitations to Capoeira. Marginalized adolescents may doubt their physical ability to perform martial arts. However, Capoeira is not restricted to just physical abilities. Young people may choose to play instruments or provide encouragement to others if they choose not to participate in the martial arts. Another limitation is that principals in schools and administrators in residential facilities may not want adolescents who are angry to engage in what they may consider as aggressive outlets, such as martial arts. Marginalized adolescents may not want to engage in a foreign art. Nonetheless, Capoeira's historical significance gives opportunities for discussions about oppression, institutionalism, and social class. A dialogue about oppression may provide a bridge to other people for youth who are reluctant to participate because of the foreign nature of the medium, as well as for administrators reluctant about physical intervention.

\section{implications for research and practice}

Implications for research concern the implementation of Capoeira and addressing whether its outcomes are better than cognitive behavioral therapy with aggressive minority adolescents. Additionally, researchers could compare and contrast differences in behavioral change between male and female adolescents to see if one benefits more than the other. There needs to be a clinical supervisor who will supervise all clinical components of the program. Although an individual who is highly trained in Capoeira will provide the bulk of the intervention, clinical oversight is essential (Twemlow, Biggs, et al., 2008). The clinical supervisor will have an ongoing involvement with the instructors of Capoeira, through consultation and supervision, as well as in evaluation, medication oversight, and counseling. The clinician's involvement will not be as intense as in regular interventions, with the primary goal being to ensure proper functioning of the clinical martial arts intervention. Clinicians would not need training in Capoeira because the martial arts aspect is distinct from the clinical component.

\section{references}

American Heritage dictionary (4th ed.). (2006). New York, NY: Bantam.

Back, A., \& Kim, D. (1979). Towards a Western philosophy of the Eastern martial arts. Journal of the Philosophy of Sport, 6, 19-28. 
Bandura, A. (1986). Social foundations of thought and action: A social cognitive theory. Englewood Cliffs, NJ: Prentice Hall.

Bandura, A. (1997). Self-efficacy: The exercise of control. New York, NY: Freeman.

Bandura, A. (2001). Social cognitive theory: An agentic perspective. Annual Review of Psychology, $52,1-26$.

Bernard, B. (1991). Fostering resiliency in kids: Protective factors in the family, school, and community (U.S. Department of Education Cooperative Agreement No. 3188A0001). Portland, OR: Western Regional Center for Drug-Free Schools and Communities.

Boneco, M. (2002). Foundations of Capoeira. Retrieved from http://www.capoeirabrasil.com

Capoeira, N. (2003). The little Capoeira book. Berkeley, CA: North Atlantic.

Capoeira, N. (2006). A street-smart song: Capoeira philosophy and inner life. Berkeley, CA: North Atlantic. Capoeira of San Jose. (2003). History of Capoeira. Retrieved from http//www.capoeirasj.com

Constantine, M. G., Hage, S. M., Kindaichi, M. M., \& Bryant, R. M. (2007). Social justice and multicultural issues: Implications for the practice and training of counselors and counseling psychologists. Journal of Counseling $\mathcal{E}$ Development, 85, 24-29.

Coopersmith, S. (1967). The antecedents of self-esteem. San Francisco, CA: Freeman.

Day, S. X. (2004). Theory and design in counseling and psychotherapy. Boston, MA: Houghton Mifflin.

Fondacaro, M. R., \& Weinberg, D. (2002). Concepts of social justice in community psychology: Toward a social ecological epistemology. American Journal of Community Psychology, 30, 473-492.

Hawkins, J. D., Catalano, R. F., \& Miller, J. Y. (1992). Risk and protective factors for alcohol and other drug problems in adolescence and early adulthood: Implications for substance abuse prevention. Psychological Bulletin, 112, 84-105.

Kazdin, A. E. (1989). Behavior modification in applied settings (4th ed.). Pacific Grove, CA: Brooks/Cole.

Kurian, M., Caterinio, L. C., \& Kulhavy, R. W. (1993). Personality characteristics and duration of American Taekwondo training. Perceptual and Motor Skills, 76, 363-366.

Lamarre, B. W., \& Nosanchuk, T. A. (1999). Judo-the gentle way: A replication of studies on martial arts and aggression. Perceptual and Motor Skills, 88, 992-996.

Law, D. R. (2004). A choice theory perspective on children's taekwondo. International Journal of Reality Therapy, 24, 13-18.

Lerner, R. M. (1982). Children and adolescents as producers of their own development. Developmental Review, 2, 342-370.

National Advisory Mental Health Council. (1996). Basic behavioral science research for mental health: Sociocultural and environmental processes. American Psychologist, 51, 722-731.

Nosanchuk, T. A. (1981). The way of the warrior: The effects of traditional martial arts training on aggressiveness. Human Relations, 34, 435-444.

Parmigiani, S., Bartolomucci, A., Palanza, P., Galli, P., Rizzi, N., Brain, P. F., \& Volpi R. (2006). In judo, Randori (free fight) and Kata (highly ritualized fight) differentially change plasma cortisol, testosterone, and interleukin levels in male participants. Aggressive Behavior, 32, 481-489.

Piquero, A. R. (2008). Disproportionate minority contact. Future of Children, 18, 59-79.

Portes, P. (1998). Making kids smarter: A guide for developing and teaching children successfully. Louisville, KY: Butler Books.

Rice, F. P., \& Dolgin, K. G. (2005). The adolescent (11th ed.). Boston, MA: Pearson.

Roysircar, G. (2009). Evidence-based practice and its implications for culturally sensitive treatment. Journal of Multicultural Counseling and Development, 37, 66-82.

Small, R., Kennedy, K., \& Bender, B. (1991). Critical issues for practice in residential treatment: The view from within. American Journal of Orthopsychiatry, 61, 327-328.

Twemlow, S. W., Biggs, B. K., Nelson, T. D., Vernberg, E. M., Fonagy, P., \& Twemlow, S. W. (2008). Effects of participation in a martial arts-based antibullying program in elementary schools. Psychology in the Schools, 45, 947-959.

Twemlow, S. W., \& Sacco, F. C. (1998). The application of traditional martial arts practice and theory to the treatment of violent adolescents. Adolescence, 33, 505-518.

Twemlow, S. W., Sacco, F. C., \& Fonagy, P. (2008). Embodying the mind: Movement as a container for destructive aggression. American Journal of Psychotherapy, 62, 1-33.

Twemlow, S. W., Sacco, F. C., \& Williams, P. (1996). A clinical and interactionist perspective on the bully-victim-bystander relationship. Bulletin of the Menninger Clinic, 60, 296-313.

U.S. Department of Education. (2000). Indicators of school crime and safety 2000. Washington, DC: U.S. Government Printing Office. 
U.S. Department of Justice. (2001). Crime and victimization statistics: National crime victimization survey. Retrieved from http//www.ojp.usdoj.gov/bjs/cvict.htm

Weisz, J. R., Sandler, I. N., Durlak, J. A., \& Anton, B. S. (2005). Promoting and protecting youth mental health through evidence-based prevention and treatment. American Psychologist, 60, $628-648$.

Wells, K. (1991). Placement of emotionally disturbed children in residential treatment: A review of placement criteria. American Journal of Orthopsychiatry, 61, 339-347. 